\title{
株状粗度モデルに作用する流体力の 評価に関する基礎実験 \\ EVALUATION OF FLUID FORCE ON COLONY-MODEL BASED ON THE FUNDAMENTAL EXPERIMENT
}

\author{
武村武 1 田中規夫 2 \\ Takeshi TAKEMURA and Norio TANAKA \\ 1学生会員 工修 埼玉大学大学院 理工学研究科（テ338-8570 埼玉県さいたま市桜区下大久保255） \\ 2正会員 工博 埼玉大学工学部助教授 建設工学科（テ338-8570 埼玉県さいたま市桜区下大久保255）
}

\begin{abstract}
Flow structures around colony-model on a flat plate, one of the vegetation type in river, were investigated by water flume experiment. Considering the characteristics of the colony of Phragmites australis, Typha angustifolia and Phragmites japonica, three parameters, distance between cylinders (L/D), aspect ratio and inclination, were decided. The two types of vortex street were visualized behind the colony-model, large eddy street and Kármán vortex street. The Strouhal number was not change with changing mean velocity. The value of drag coefficient, $C_{d}$, was changed based on $\mathrm{L} / \mathrm{D}$. When the aspect ratio was low, the $C_{d}$ increased gradually with increasing $\mathrm{L} / \mathrm{D}$. But, it become almost constant value when the ratio was larger than 4 . Moreover, the $C_{d}$ decreased significantly with increasing the inclination of the colony-model. The $C_{d}$ of the colony-model can be arranged by using $\mathrm{L} / \mathrm{D}$, aspect ratio and inclination of it.
\end{abstract}

Key Words : colony-model, drag coefficient, vortex street, Strouhal number

\section{1.はじめに}

河川に存在する植物が河川流量・水位へ与える影響を 考慮する場合，正方格子もしくは千鳥格子状に配置され た円柱群により植生をモデル化し，流れの受ける運動量 損失や物体により形成される乱流せん断力特性を評価す るなどの形で多くの検討がなされてきた1)。しかし，河 道内が樹林化 ${ }^{2)} し て い く$ 初期段階では，「株」を基本単 位とした草本・木本が点在する状態がしばしば形成され る. そのような株状群落の場合は, 一様な粗度として植 生を考慮するのではなく，透過性を有する粗度が配置さ れていると考えるのが適切と考えられる゙．しかし，河 川流においてそうした検討はあまりなされておらず，樹 林化の初期繁茂状態における河川流の運動量損失に対し て植生が与える影響は不明の点が多い. さらに, 通常の 河川流を想定した場合, 植生のアスペクト比（植生の没 水高さ/株状群落の直径) は通常小さいため, 植生の後 流域におけるカルマン渦列の生成状況と共に, 植生前面 の底面付近に形成される馬蹄形渦との関連も，株にかか る流体力特性を評価する上で重要な要素となる.
株状群落は飛砂の発生に関して円柱群を粗度として扱 うケース ${ }^{1} や ，$ 没水樹林が流れに与える影響を表現する ために，単体の物体に空隙をあけた粗度による検討がな されてきた4).

一方, 株を形成する以前の流れに関しては, 単独円柱 や複数円柱の相互干渉に関する研究が参考になる. 流れ の中の単円柱に作用する流体力に関する研究は, 従来数 多く行われており5), 6), 円柱前面に生成される馬蹄形渦 の特性に関する研究も行われている5). また, 円柱が複 数本設置されている場合においては, 剥離流れの相互干 渉により円柱周りの流れが複雑になり, 単独円柱におけ る結果とは大きく違うことが知られているグ。この問題 に対する研究として, 流れの中に設置された複数円柱の 相互干渉に関する研究が行われているわ，8), 9). 多くの既 往研究は風洞実験を用いた高アスペクト比の実験である ため, 本研究目的のような低アスペクト比での知見は不 足している. そのため, 本研究で想定する「株」に対し て既往の結果をそのまま適用することは難しい．

そこで，本研究では，河川に繁茂する植生を想定し， 株周りの流れ場を明らかにするために, 無次元化した茎 間距離（円柱間距離：L/D）とアスペクト比，株の傾斜 
角を変化させ，株にかかる流体力特性を調べることで, 流れの中に存在する株状群落の特性を流体力学的に明ら かにすることを目的とする.

\section{2. 実験装置および方法}

\section{(1) 実験装置}

水理模型実験は, 全長 $15 \mathrm{~m}$, 幅 $0.5 \mathrm{~m}$, 哚さ $0.4 \mathrm{~m}$ の矩 形断面を有する可変勾配開水路 (可傾範囲 $0 \sim 1 / 50$, 最 大流量 $0.1 \mathrm{~m}^{3} / \mathrm{s}$ ) にて行った. 粗度としての円柱群モデ ルを上流から $8.5 \mathrm{~m}$ 地点（流水が十分に安定した場所） の水路中央に 1 つ設置し, 上流から $8 \mathrm{~m}-9 \mathrm{~m}$ を実験観測区 間とした。 断面平均流速は $0.1,0.2,0.4 \mathrm{~m} / \mathrm{s}$ のアース

（株状粗度モデルの外周直径を代表長さとした場合, $\left.R e=3.5 \times 10^{3} \sim 4.5 \times 10^{4}\right)$ で，実験を行った.

株状粗度モデルにかかる抗力を測定するにあたって, 2分力計 (SSK社製: LB00-000, 計測方向 : $X, Y$ 方向) を使用した. 本2分力計は, 計測最大荷重1Nで分解能 1/1000という, 微少な力の計測に適したものである. 図 一2に設置図を示す. 流速は, 電磁流速計（（株）ケ ネック製，VM2000型（本体部），VMT2-200-04P型（検 出部））を用いて計測を行った. 両者とも, 計測は, サ ンプリング周波数を $100 \mathrm{~Hz}$, 計測時間を 30 秒間とし, 時 間平均値，ならびに変動成分の特性を求めた。 また，本 研究におけるレイノルズ数 $(R e)$, 抗力係数 $\left(C_{d}\right)$, ス トロハル数 $\left(S_{h}\right)$ は,

$$
\begin{aligned}
& R e=\frac{U D}{v} \\
& C_{d}=\frac{2 F}{\rho A U^{2}} \\
& S_{h 1}=\frac{f D}{U}, S_{h 2}=\frac{f D^{\prime}}{U}, S_{h 3}=\frac{f D^{\prime}}{\left(U-u_{1}\right)}
\end{aligned}
$$

でそれぞれ定義する．ここに，U(m/s) は断面平均流 速, $v\left(\mathrm{~m}^{2} / \mathrm{s}\right)$ は水の動粘性係数, $F(\mathrm{~N})$ は抗力, $\rho\left(\mathrm{kg} / \mathrm{m}^{3}\right)$ は水の密度, $A\left(\mathrm{~m}^{2}\right)$ は株状粗度モデルの水平投影面積, $f(\mathrm{~Hz})$ は渦の発生周波数, $D^{\prime}$ 'は代表長さ $(=A / h), h$ （m）は水深，Dは使用円柱直径， $u_{l}$ は株状粗度モデル 背後における透過流速である.

株状粗度モデル周りにおける流れ場の可視化には，染 料（Aniline Blue）を用い，可視化実験の流速は，0.04， $0.1,0.4 \mathrm{~m} / \mathrm{s}$ のケースとした.

\section{(2) 使用モデル}

既往の研究により，2円柱，3円柱の配置の違いによる 円柱にかかる抗力の検討は行われているが，株を想定し た場合にはより多くの円柱が必要である。 そこで，本研

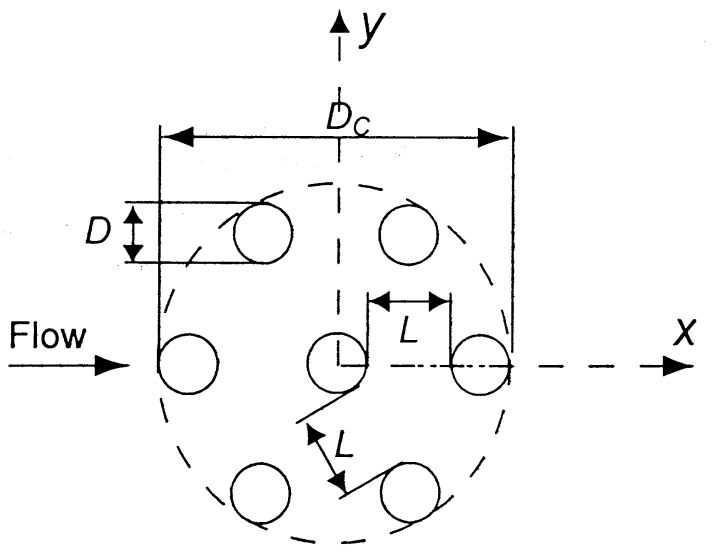

図一1 株状粗度モデルの概型

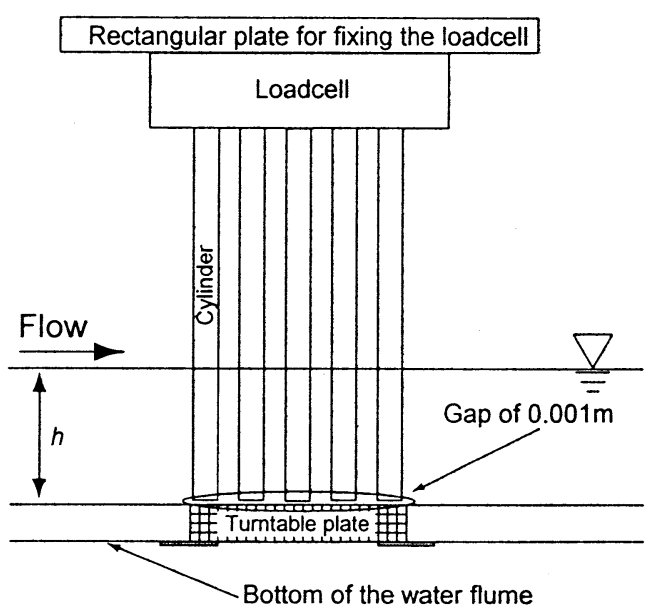

図一2 株状粗度モデルの設置図

表 -1 実験条件一覧表 $(U$ : 断面平均流速 $(\mathrm{m} / \mathrm{s})$, $h$ : 水媣 $(\mathrm{cm}), D$ : 使用円柱直径 $(\mathrm{cm}), \bigcirc$ : 計測実 施, - :未計測)

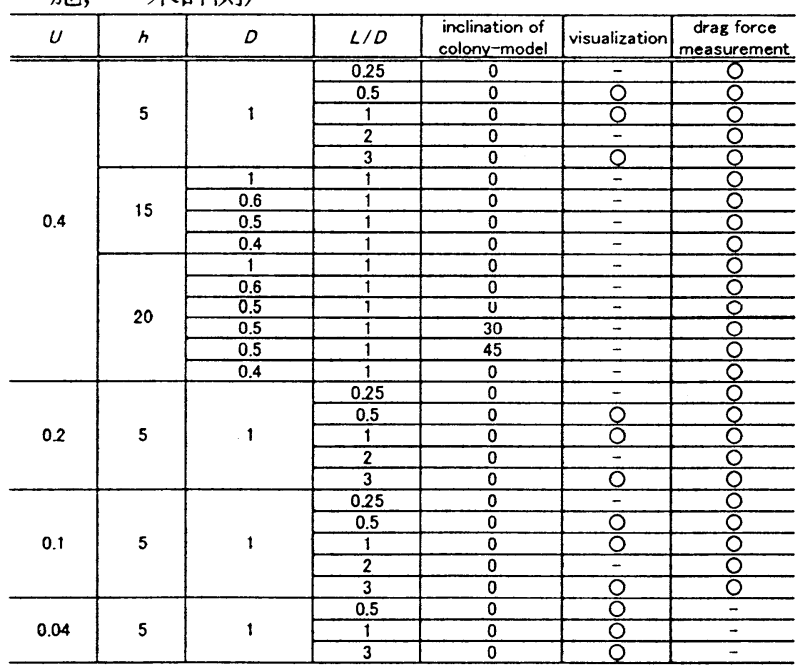

究では, 既往の研究と比較検討が可能な「縦 2 円柱配

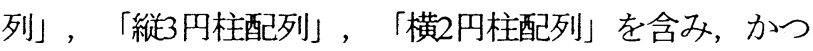
外周部に囲まれた内部円柱を有する形で株状粗度モデル を設定した。株状粗度モデルは，直径 $0.4 ， 0.5 ， 0.6$ ， $1 \mathrm{~cm}$ の円柱を用いて，隣り合うすべての円柱間隔を等し くする条件，すなわち正六角形に中心を加えた7本で作 


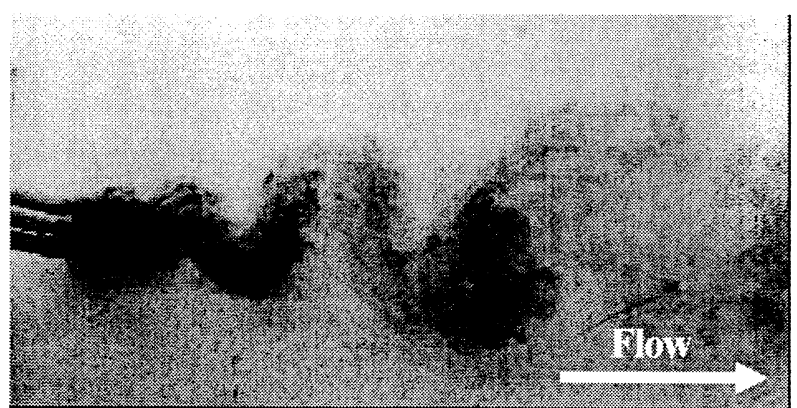

(a)

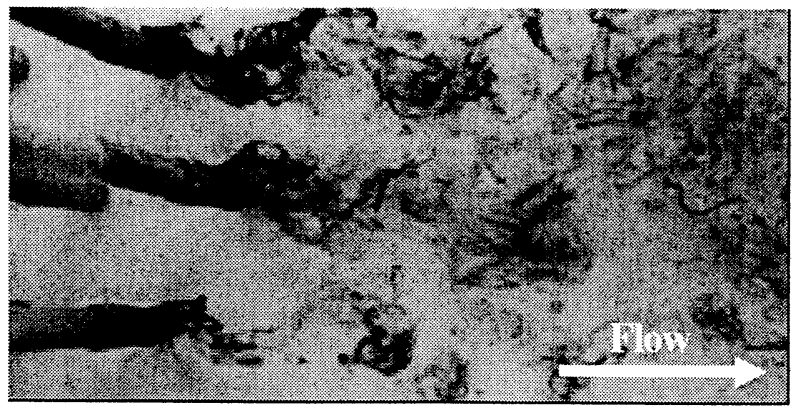

(c)

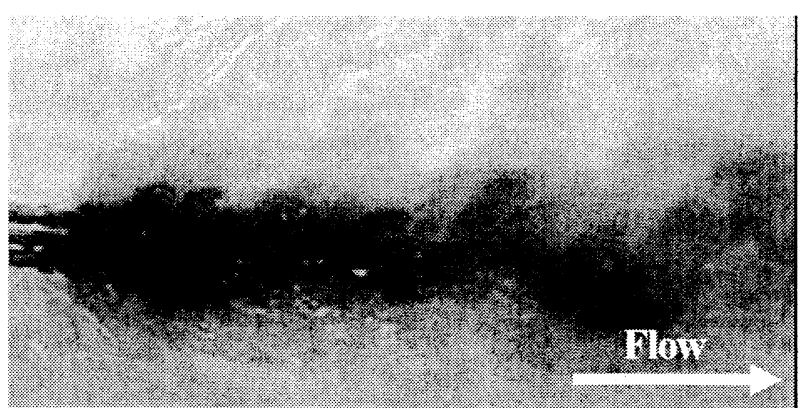

(b)

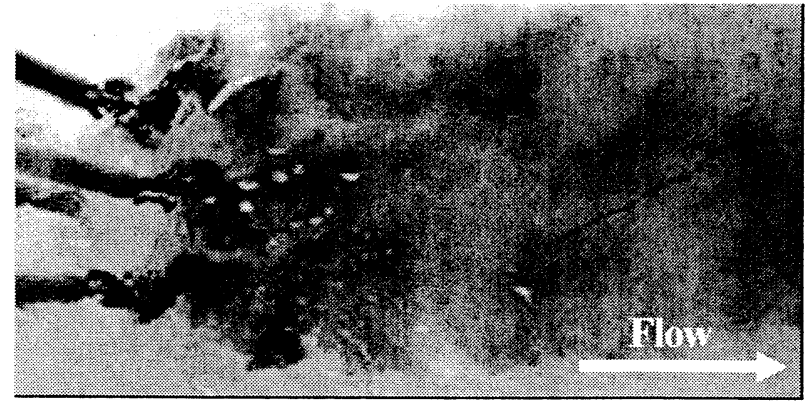

(d)

図一3 株状粗度モデル背後における渦列の生成状況

(a) $L / D=0.5, \quad L=0.04 \mathrm{~m} / \mathrm{s}, \quad$ (b) $L / D=0.5, \quad L=0.4 \mathrm{~m} / \mathrm{s}$

(c) $L / D=3, \quad U=0.04 \mathrm{~m} / \mathrm{s}, \quad$ (d) $L / D=3, \quad L=0.4 \mathrm{~m} / \mathrm{s}$

成した，株状粗度モデルの概型を図一1に，株状粗度モ デルの設置イメージを図一2示す. また, 流水による植 生の変形を考慮するために, 株状粗度モデルを傾斜させ た. 傾斜角は, Tanaka et al. ${ }^{10)}$ を参考にし，30度，45度の 2ケースとした. 株状粗度モデル高さは自由水面を十二 分に超える高さとした. 実験条件一覧を表一1に示す. 株状粗度モデルの傾斜角は，鉛直上向きから流下方向人 傾けたときの角度である.

\section{3. 実験結果}

\section{(1) 株状粗度モデル周りの流れの变化}

株状粗度モデル背後における流れの可視化の様子を示 したのが，図-3(a)〜 (d) である. $L / D=0.5$ ケース（(a)， (b)）においては, 株状粗度モデル直後では, 迂回流と株 状粗度モデル背後に出来る死水域とのせん断層に沿って 小さな渦（以後, 小規模渦列）が発生している. これは, 渦の発生状況の観察から, 個々の円柱から発生したもの であると考えられる. 後方では, 株状粗度モデル全体を 基本とした渦列（以後, 大規模渦列）が発生しているの が確認できる. $L D=1$ においては，小規模渦列は確認で きるが, 大規模渦列の発生地点は, $L D=0.5$ よりも下流 側に移動している． $L D=3$ (図一-3(c)，(d)）においては, 各円柱の背後において, カルマン渦列の発生が確認でき るが，大規模渦列は明確には確認できなかった。

株状粗度モデル周辺における流れ特性を見るために,

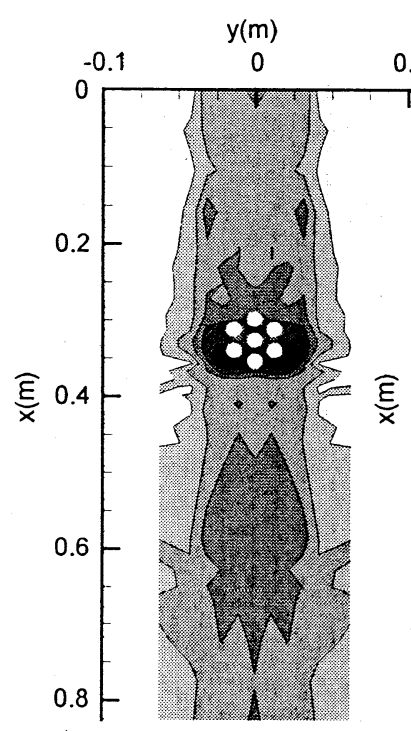

(a)

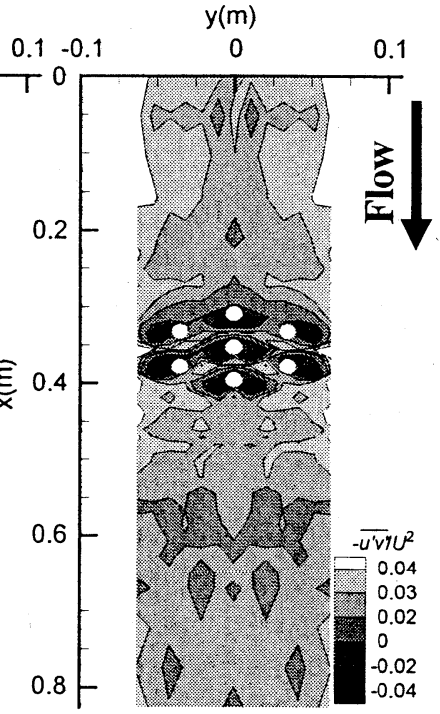

(b)
図-4 レイノルズストレスの分布 $(U=0.4 \mathrm{~m} / \mathrm{s})$ (a) $L D=0.5$, (b) $L / D=3$

レイノルズストレスの分布を測定した．その結果を図一 4に示す.ここで，無次元レイノルズ応力は- $\overline{u^{\prime} v^{\prime}} \Lambda^{2}$

$\left(u^{\prime}: X\right.$ 方向の流速の変動成分, $v^{\prime}: Y$ 方向の流速の変動成 分）とする. $L / D=0.5$ においては, 株状粗度モデル背後 において，大きく值が減少している．また，株状粗度モ デル下流側に，モデルと同様の幅で周辺部よりレイノル ズストレスが小さくなっているのも確認できる.これは, 
株状粗度モデルより発生した渦列は，隣り合う円柱との 距離が短いため，すぐに合体してしまうため，渦列間の せん断層が明瞭に出ない事と, 株状粗度モデル背後に大 きな再循環領域が形成されているためと考えられる。 一 方，L/D=3においては，個々の円柱の背後で大きく值が 減少している. また, 株モデル背後においては, 帯状に 値が小さいところが存在している.これは，個々の円柱 から発生したカルマン渦列がそのまま下流に流れていき， その渦列によってせん断層が帯状に形成されているため と考えられる.

ここで, 株状粗度モデル背後に発生した渦列の発生周 期を計測するために, $L D=0.5 ， 1 ， 3$ のケースにおいて, ビデオカメラで後流の様子を撮影し, ストロハル数の検 討を行った，その結果を図一5に示す．図中のプロット に示されたエラーバーは, 標準偏差を示す. (a)小規模渦, (b)大規模渦ともに, 平均流速が増加しても, ストロハル 数は大きく変化していないことがわかる. 小規模渦の結 果においては，LDの違いにより，ストロハル数は大き く変化していない。一方，大規模渦列の結果において (図一3 (b) )，ストロ八ル数 $\left(S_{h 2}\right)$ を算出するときに 用いる流速が断面平均流速（U）の場合，值が小規模渦 列の結果より小さく出ている。一方，ストロハル数

$\left(S_{h 3}\right)$ を算出するときに用いる流速に断面平均流速と平 均透過流速の差 $\left(U-u_{1}\right)$ を用いた時は，小規模渦列の結 果より大きくなっていることが分かる.

以上の結果より，放出渦の傾向は実験流速の違いによ り大きく変化はしていないと考えられる. 複数円柱周り の流れは，Re数よりもL/Dに依存すると報告されており 11)，本実験においても同様のことがいえると考える.

次に，株状粗度モデルにおける透過流速の実験結果を 図一6に示す．L/Dが0.25から0.5に増加するとき，円柱間 に打ける透過流速 $\left(u_{l}\right)$ は大きく増加し, その後緩やか に増加している。一方, 株モデルにおける迁回流速 $\left(u_{\text {detrur }}\right)$ は, 透過流速 $\left(u_{1}\right)$ とは逆の傾向となっている. $L / D$ が0.25から0.5に増加するとき, 迂回流速 $\left(u_{\text {detorr }}\right)$ は 大きく減少し，その後は緩やかに減少している. 可視化 実験において，L/D<0.5では，透過流 $\left(u_{1}\right)$ と迁回流 $\left(u_{\text {derour }}\right)$ の流速差が非常に大きい事から，株モデルの背 後に再循環領域が確認でき，それ以上では，流速差が小 さくなることから，確認しづらくなると考えられる.

以上より， $L D=0.5$ では，株状粗度モデル全体を基本

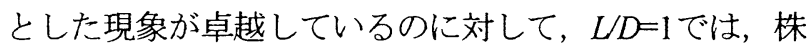
状粗度モデル全体と個々の円柱により発生するカルマン 渦列が混在し, 渦放出特性が遷移し始め, $L D=3$ 付近で は個々の円柱による現象が卓越していると考えられる.

\section{（2）株状粗度モデルにおける流体力の計測結果}

図一7に実験流速ごとの株状粗度モデル全体としての

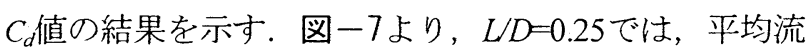
速により違いはあるが， $C_{d}=1$ 程度となっている。 これ

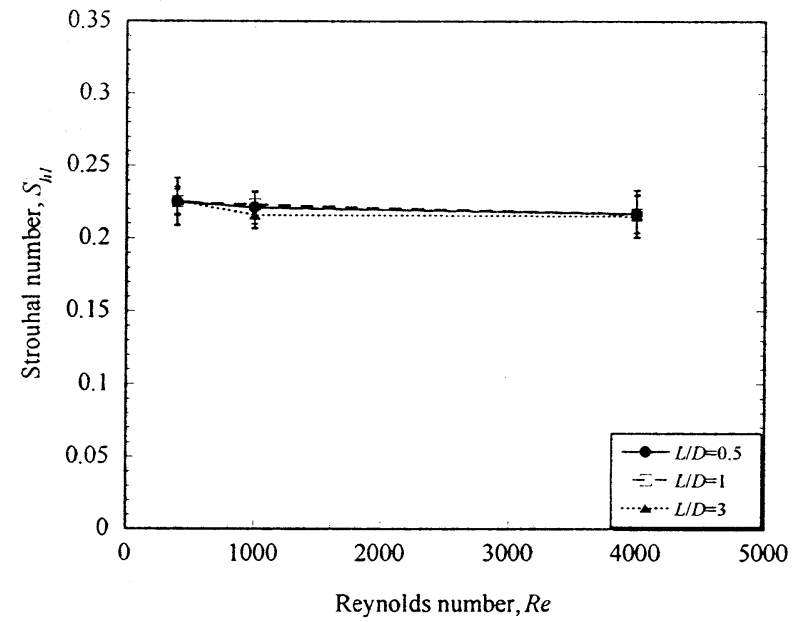

(a)小規模渦列

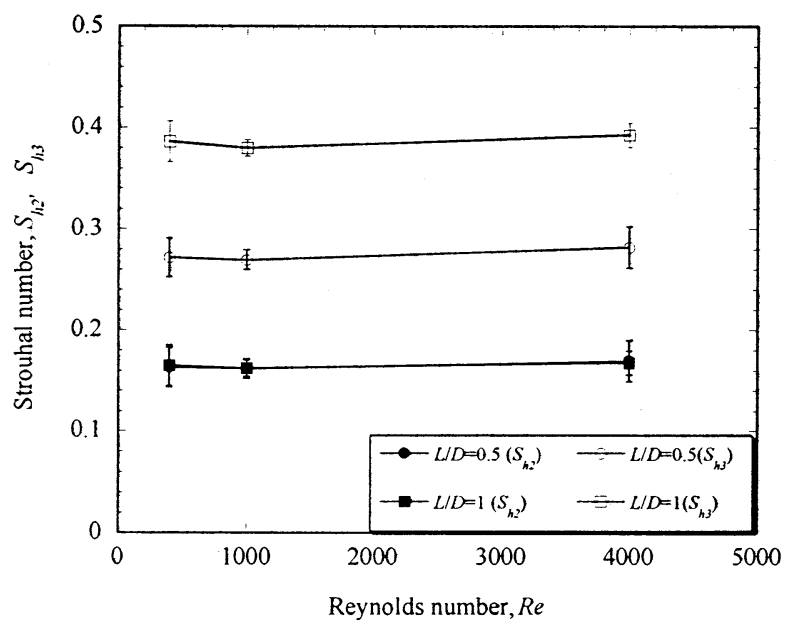

(b)大規模渦列

図-5 ストロハル数の計測結果

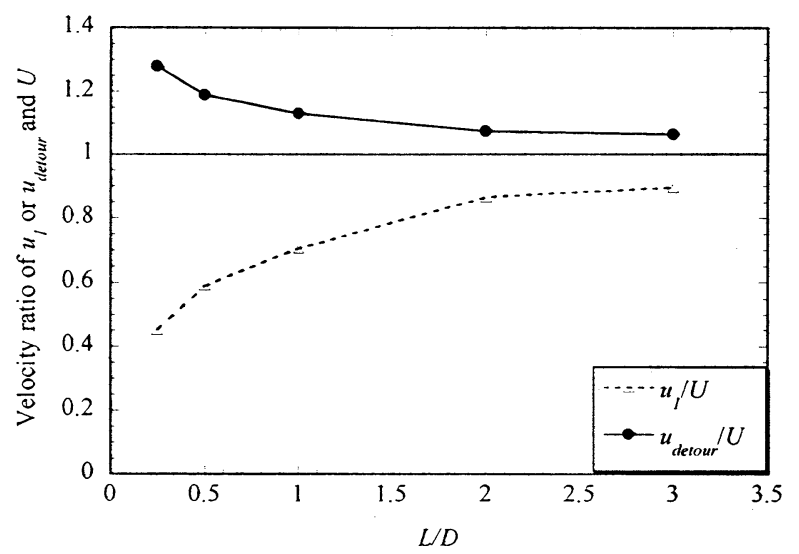

図-6 透過流速と迁回流速の計測結果

は，株状粗度モデルと同程度の外周直径を有する単独円

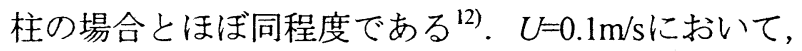
$0.25<L D<1$ 範囲では， $C_{d}$ 值は約1から1.2まで増加して いるが， $L D>1$ の範囲においては， $C_{d}$ 值に大きな変化は 見られない．この傾向は，平均流速が増加しても大きく

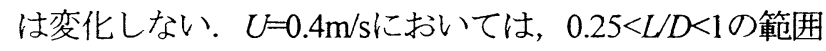
では，C，値は約1.1から1.3まで増加している. 


\section{（3）株状粗度モデルにおけるアスペクト比の影響}

河川域をイメージした場合, 水深変化に伴い植生のア スペクト比は大きく変化する．そこで，株状粗度モデル の外周直径を基本長さとした場合のアスペクト比 $(h D c)$ を変化させた実験結果を図一8に示す．本結果 より， $h D c か ゙ 1 か ら 4 へ$ 増加するに伴い， $C_{d}$ 值は大きく増 加している．一方， $h D c>6$ の範囲では， $C_{d}$ 值はそれほ ど大きく変化していない，その増加率は， $h D c=1$ を基準 にしたとき， $h D c=4$ では約 $20 \%, h D c=7$ では約 $25 \%$ の増 加となっていることが確認できる。

\section{(4) 株状粗度モデルの傾斜角と $C_{d}$ d值の関係}

流水の影響を受ける場合，草本植生は剛体でないこと から，弾性変形をすることは容易に推察できる. しかし， 本株状粗度モデルでその変形を模擬することは難しいこ とから，モデルの傾斜により模擬した. 傾斜角と $C_{d}$ 值の 関係を図一9に示す．図中の実線は，単円柱が垂直に設 置されている場合の実験結果である，本結果より，株状 粗度モデルの傾斜角度が増加するにしたがって，C $C_{d}$ 值は 大きく減少している．0度の時を基準にすると，30度の 時で約 $15 \% ， 45$ 度の時で約30\%の減少が確認できる.

\section{4. 考察}

\section{(1) 流れの構造の変化}

可視化実験より， $L D=0.5$ のケースにおいては，個々 の円柱から生成される明瞭なカルマン渦列が確認できず, 株状粗度モデル背後に死水域を形成し，迁回流とのせん 断層にそって渦（小規模渦）の発生が確認できる.また, $L D=1$ から3に増加することにより，株状粗度モデル背後 の死水域が小さくなる. そして, $L / D=3$ のケースにおい ては，可視化実験により個々の円柱背後におけるカルマ ン渦列は確認できたが，大規模渦列を明瞭に確認するこ とは困難であった．また，株状粗度モデル背後における 底面流況の観測より, $L / D=0.5$ に比べて,$L D=1$ では背後 に生成される死水域が細長くなることが確認出来た。こ れは, $L D$ の増加に伴い死水域の形成範囲が大きく変化 し，後流の特性が大きく変化するためと考えられる. 次 に，大規模渦列の発生特性を整理するのに用いたストロ 八ル数 $\left(S_{h 2}, S_{h 3}\right)$ は，小規模渦列の結果 $\left(S_{h l}\right)$ と異 なっていた，渦列の循環を考えた場合，平均流速（U) と透過流速 $\left(u_{l}\right)$ との流速差で，発生渦特性は決まると 考えられる。しわし， $S_{h 2} ， S_{h 3}$ は0.2よりも大きくずれて いる. この事より，現在ストロハル数を算出するときに 用いている代表長さ $\left(D^{\prime}\right)$ はL/Dの変化により変化しな いことが，ストロハル数の值が大きく違ってしまう要因 と考えられ，代表長さに再考の余地があると考えられる.

(2) $L / D の$ 変化に伴う株状粗度モデルのC值の変化

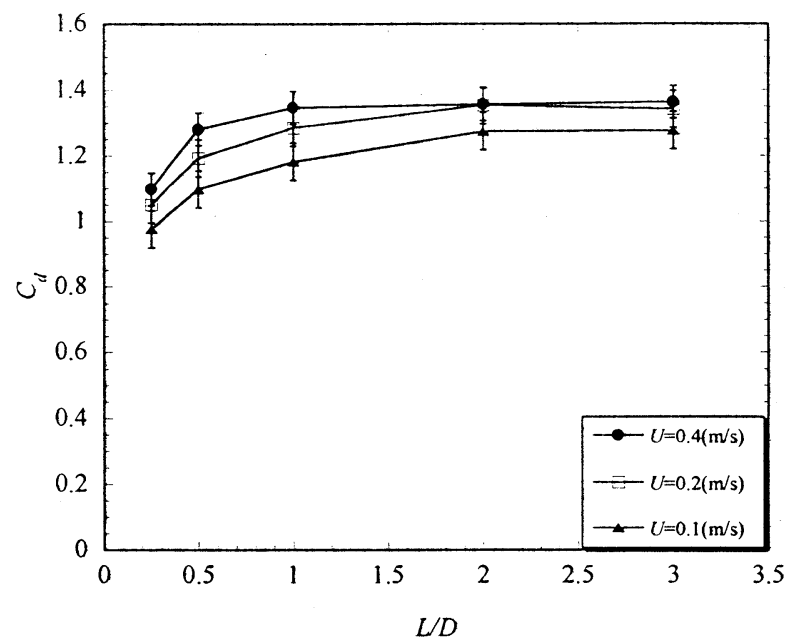

図ー7＼cjkstart株状粗度モデルにおけるCd值の結果

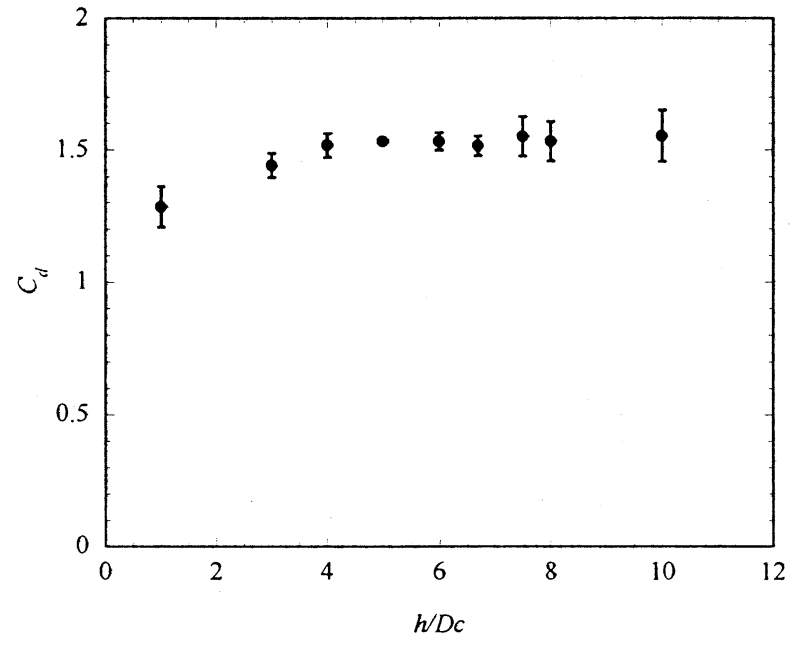

図ー8 アスペクト比の変化に伴う $C_{d}$ 值の変化

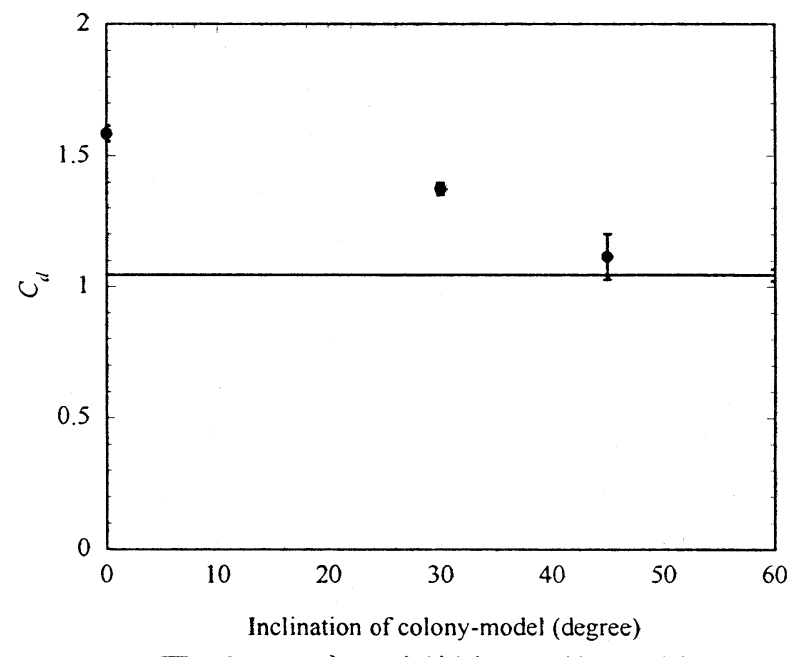

図-9 モデルの傾斜角〉C值の関係

株状粗度モデルにおけるC $C_{d}$ 值について考察する. 図一 7の結果より，流速の違いにより $C_{d}$ 値に若干の差異は認 められるが, $L D$ の増加に伴い $C_{d}$ 值は増加し，その後ほ ぼ一定となっている．これは，LDが大きくなることに より，透過流速が大きくなり，背後に位置する円柱にか かる抗力が大きくなる．また，円柱から放出される渦の 
相互干渉も小さくなる，などが要因であると考える.

(3) アスペクト比と傾斜角の変化が株状粗度モデルの $C_{d}$ 值に及ぼす影響

アスペクト比が1から4に増加するとき， $C_{d}$ 値は大きく 増加した. これは, 水深の増加に伴い, 株状粗度モデル 前面底部に生成される馬蹄形渦の大きさが，相対的に小 さくなり，株状粗度モデルにおける抗力を受ける有効面 積が大きくなるためと考えられる.

次に，株状粗度モデルの傾斜角について見てみると， 角度の増加に伴い， $C_{d}$ 値は减少するという結果を得た。 これは, 傾斜角の増加に伴い, 株状粗度モデル自体が流 線型に近づくため, モデル前面部における抗力が大きく 減少したためと考える. また，傾斜角45度の時の $C_{d}$ 值は, 単円柱のものよりまだ大きくなっていることから, 株状 粗度モデルの $C_{d}$ 值は既往の円柱の值を適用することが難 しいと考えられる.

\section{5. おわりに}

一様流中に設置した株状粗度モデルに働く流体力を, 水理模型実験により検討した. その結果, 以下の点が明 らかとなった。

1) 株状粗度モデルにおける透過流速と迂回流との流速 差が，モデル背後の死水域の形成状態に大きく影響 を与えている. これは, 株状粗度モデル背後に生成 される3種類の渦列によっても観察され, $L / D=1$ 付近 で, 株状粗度モデル周りの流れが「群」から「個」 一と推移し始める.

2) 株状粗度モデルとしての $C_{d}$ 值は, $L D=0.25$ から 1 まで は，大きく増加し，それ以上ではそれほど変化しな い. また， $L / D<0.5$ では株状粗度モデル全体を取り囲 むようにして前方剥離域の境界線が生成され, 株状 粗度モデル背後では, 迁回流と株状粗度モデル背後 に出来る死水域とのせん断層に沿って，小規模渦列 が確認され，その後大規模渦列となる。しかし， $L D>1$ の範囲では, $L / D$ の増加に伴い, 大規模渦列は 確認しづらくなり，個々の円柱の背後に生成される カルマン洞列が優先するようになる.

3) 株状粗度モデルの $C_{d}$ 值に対して, アスペクト比の変 化の影響は大きい. 特に, 水梁が浅い場合は, アス ペクト比が小さくなることから， $C_{d}$ 值が大きく変化 すると考えられる.

4）株状粗度モデルを傾斜させた場合， $C_{d}$ 值は大きく減 少する。これは，株状粗度モデルの形状が傾斜によ り流線型に近づくため, 前面部における抗力が大き く減少したためと考えられる.

以上の事から，河川に繁茂する植生を考虑する場合，

$L D<1$ では，株としての特性が特に際立つことから，株
状群落の配置を考慮した解析を行うべきである.

最後に, 本研究は, 株状粗度モデルの基礎的な特性を 検討するために，限定的な条件の下で実験を行った．株 は単体で生存しているのではないので，今後は株同士の 相互干渉, 植生の流水による変形等について, さらに検 討する必要性があると考える.

謝辞: 本研究を行うにあたって, 埼玉大学水理工学研究 室の城野裕介氏, 小川友浩氏, 八木澤順治氏, 竹松紘之 氏には実験を手伝って頂いた，記して謝意を表します。

\section{参考文献}

1) Musick, H. B., Trujillo, S. M. and Truman, C. R. : Wind-tunnel modelling of the influence of vegetation structure on saltation threshold, Earth Surface Processes and Landforms, Vol. 21, pp.589-605, 1996.

2) Järvelä, J., Flow resistance of flexible and stiff vegetation: a flume study with natural plants, J. Hydrology, Vol. 269, pp.44-54, 2002.

3）武村武，田中規夫，小川友浩 : 透過性のある株状群落周辺 の局所流と洗掘現象, 水工学論文集, 第48巻, pp.16211626, 2004.

4) Castro, I. P.: Wake characteristics of two-dimensional perforated Plates normal to an air-stream, J. Fluid Mech., Vol. 46, No. 3 , pp.599-609, 1971.

5) Baker, C. J. : The turbulent horseshoe vortex, J. Wind Engineering and Industrial Aerodynamics, Vol. 6, pp.9-23, 1980.

6) Okamoto, T. and Yagita, M. : The experimental investigation on the flow past a circular cylinder of finite length placed normal on the plane surface, Bulletin of the JSME, Vol. 16, No. 95, pp.805$814,1973$.

7) Tatsuno, M., Amamoto, H. and Ishi-i, K. : Effects of interference among three equidistantly arranged cylinders in a uniform flow, Fluid Dynamics Research, Vol. 22, pp.297-315, 1998.

8) Zdravkovich, M. M. : Review of flow interference between two circular cylinders in various arrangements, Trans. ASME J. Fluid Engineering, Vol. 99, pp.618-633, 1977.

9) Lam, K., Li, J. Y. and So, R. M. C. : Force coefficients and strouhal numbers of four cylinders in cross flow, J. Fluids and Structures, Vol. 18, pp.305-324, 2003.

10) Tanaka, N., Kitakami, Y., Ogawa, T. Asaeda, T · Fffect of stembreaking caused by flood on the transition of wetland vegetation in old river trace, Proc., $4^{\text {th }} I S E H \& 14^{\text {th }} L A H R-A P D, 2004$ (in press).

11) Sumner, D., Wong, S. S. T., Price, S. J. and Païdoussis, M. P. : Fluid behavior of side-by-side circular cylinders in steady crossflow, J. Fluids and Structures, Vol. 13, pp.309-338, 1999.

12) Schlichting, H., : Boundary-layer theory, 7th ed., McGraw-Hill, p.17, 1979.

(2004.9.30 受付) 